\title{
Fertility and Sterility
}

\section{Is conception by in-vitro fertilisation associated with altered antenatal and postnatal growth trajectories? \\ --Manuscript Draft--}

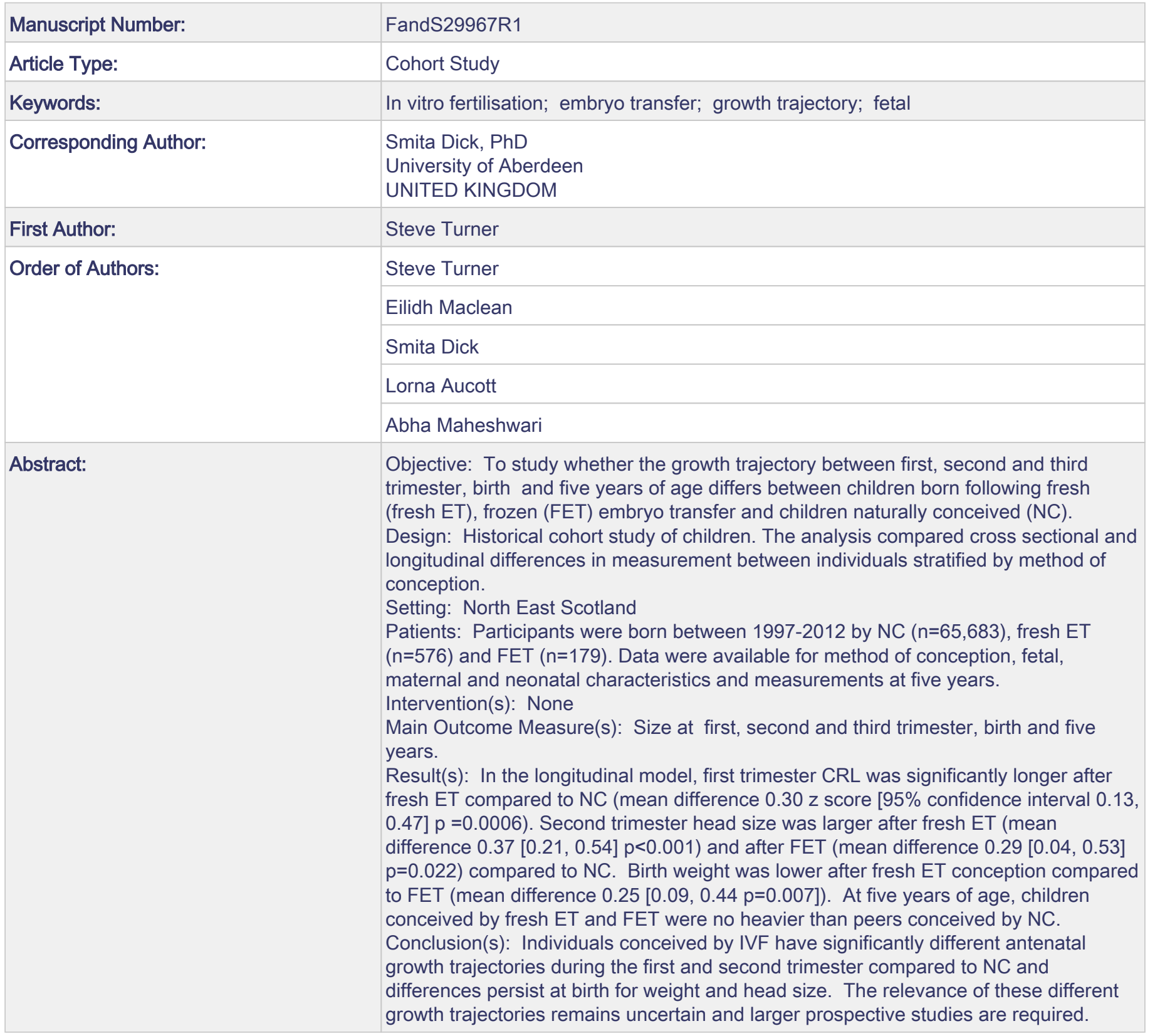


Running Title: Growth trajectory and in-vitro fertilisation

FandS29967 decline and resubmit

Is conception by in-vitro fertilisation associated with altered antenatal and postnatal growth trajectories?

Steve Turner $\mathrm{MD}^{1, *}$, Eilidh Maclean $\mathrm{MBChB}^{1}$, Smita Dick PhD ${ }^{1}$, Lorna Aucott PhD², Abha Maheshwari $\mathrm{MD}^{3}$

${ }^{1}$ Child Heath, Royal Aberdeen Children's Hospital, University of Aberdeen, Aberdeen AB25 2ZG, UK.

${ }^{2}$ Health Services Research Unit, University of Aberdeen, Aberdeen AB25 2ZD, UK.

${ }^{3}$ Aberdeen Fertility Centre, NHS Grampian, Foresterhill, Aberdeen AB25 2ZL, UK.

*Correspondence address: Child Health, Royal Aberdeen Children's Hospital, Aberdeen, AB25 2ZG, UK. E mail: s.w.turner@abdn.ac.uk.

\section{Capsule}

There was increase in child weight after IVF conception, but the antenatal growth trajectory of pregnancies following frozen embryo transfer was more stable compared to those of fresh embryo transfer. 


\section{ABSTRACT}

Objective: To study whether the growth trajectory between first, second and third trimester, birth and five years of age differs between children born following fresh (fresh ET), frozen (FET) embryo transfer and children naturally conceived (NC).

Design: Historical cohort study of children. The analysis compared cross sectional and longitudinal differences in measurement between individuals stratified by method of conception.

Setting: North East Scotland

Patients: Participants were born between $1997-2012$ by NC $(n=65,683)$, fresh ET $(n=576)$ and FET $(n=179)$. Data were available for method of conception, fetal, maternal and neonatal characteristics and measurements at five years.

\section{Intervention (s): None}

Main Outcome Measure(s): Size at first, second and third trimester, birth and five years.

Result(s): In the longitudinal model, first trimester CRL was significantly longer after fresh ET compared to NC (mean difference $0.30 \mathrm{z}$ score [95\% confidence interval $0.13,0.47] \mathrm{p}=0.0006$ ). Second trimester head size was larger after fresh ET (mean difference $0.37[0.21,0.54] p<0.001$ ) and after FET (mean difference $0.29[0.04,0.53] p=0.022$ ) compared to NC. Birth weight was lower after fresh ET conception compared to FET (mean difference $0.25[0.09,0.44 p=0.007])$. At five years of age, children conceived by fresh ET and FET were no heavier than peers conceived by NC.

Conclusion(s): Individuals conceived by IVF have significantly different antenatal growth trajectories during the first and second trimester compared to NC and differences persist at birth for weight and head size. The relevance of these different growth trajectories remains uncertain and larger prospective studies are required.

Keywords: in vitro fertilisation / embryo transfer / growth trajectory /fetal 


\section{INTRODUCTION}

Infertility affects one in seven couples (1) and treatment with IVF with or without ICIS has resulted in the birth of over 8 million babies worldwide. Whilst the benefits of IVF/ICSI to parents who cannot conceive without intervention are clear, there is the potential that offspring conceived by IVF/ICSI may be at increased risk for adverse health outcomes.

Conception following IVF/ICSI has been linked with an increased risk for major congenital anomalies, perinatal mortality, premature delivery, low birth weight and small for gestational age (SGA) (2-5). Risk for adverse perinatal outcomes (including reduced birth weight, premature delivery and SGA) were lowest after natural conception, highest after fresh embryo transfer (fresh ET) and intermediate after frozen thawed embryo transfer $(\mathrm{FET})(5,6)$.

In a number of studies, authors have shown an association between conception after frozen thawed embryo transfer and large for gestational age (LGA) and macrosomia compared to fresh embryo transfer and natural conception (7). What has not been explored is whether conception after IVF/ICSI is associated with differences in anthropometric measurements at various stages before birth and for the offspring beyond the perinatal period, and in particular with childhood weight. In a study by Miles et al. (8), children born following IVF/ICSI treatment were taller (but not heavier) and a study by Sutcliffe et al. (9) reported reduced risk for being overweight by 5 years of age after IVF/ICSI conception when compared to NC. Haan et al. (10) did not find a significant difference for height, weight and BMI at school entry (age 4-6 years of age) in a cohort of children born following fresh ET, FET and naturally conceived. Hence there is uncertainty about the relationship between IVF/ICSI and childhood anthropometric measurements.

The objectives of this study were to link routinely collected data to create a virtual birth cohort and then determine whether the growth trajectory in pregnancies after IVF/ICSI is different to peers conceived after natural conception (NC) in the first, second and third trimesters, birth and five years of age. In addition, we also explored the differences in growth trajectory between fresh ET and FET. 


\section{MATERIALS AND METHODS}

\section{Study Design and Participants}

This was a retrospective cohort study linking data from three separate databases: the Aberdeen Fertility Centre Database (AFC), the Aberdeen Maternity and Neonatal Databank (AMND) and the Study of Trends in Obesity in North East Scotland (STONES). The study was approved by the North of Scotland Research Ethics Committee (reference 15-NS-0045) and the AMND Steering Committee (reference SB/AMND15).

\section{Aberdeen Fertility Centre Database}

Aberdeen Fertility Centre is the only centre providing either private or public fertility treatment in the North and East of Scotland including the Grampian and Highland regions, and the Shetland and Orkney islands (11) and data on all patients receiving fertility treatment in Aberdeen and who delivered at Aberdeen Maternity Hospital (AMH) are included. The data extracted for this study included: the type of embryo transfer (fresh or frozen) and stage of transfer (cleavage or blastocyst).

\section{Aberdeen Maternity and Neonatal Databank}

The AMND contains routinely collected data on all pregnancies occurring at $A M H$ (12). AMH is the only maternity hospital in the city of Aberdeen, and also provides tertiary maternity care to the entire region of North East Scotland including the Grampian region and the Orkney and Shetland islands. For this study the following maternal characteristics were extracted from the database: age, parity, BMI, height, smoking status and socioeconomic status using Carstairs index (13) (an index of deprivation used in Scotland which takes into account car ownership, occupational social class, overcrowding in households, male unemployment and postcode sectors). The first trimester measurement was crown rump length which is typically measured in our centre at 11 weeks gestation. Second trimester measurements are taken at approximately 20 weeks gestation in Aberdeen and include, biparietal diameter (BPD), femur length ( $F L)$ and abdominal circumference $(A C)$. Third trimester measurements are taken for obstetric reasons, e.g. low lying placenta, small for dates fetus, and include BPD, FL and 
AC. Estimated fetal weight (EFW) in the second and third trimesters was calculated using the method methodology (15). The data collected from birth records included gestation at birth, singleton/multiple gestation pregnancy, birth weight, birth length and occipito frontal circumference (OFC). Multiple gestation pregnancies were excluded from the analysis.

\section{STONES}

The STONES database contains routinely collected data on the height and weight of children on school entry at an average of 5.5 years. Data were available in approximately $70 \%$ of all children at school entry. For this study height, weight and BMI were extracted from the STONES database and z scores were derived using the 1990 standard (16). The International Obesity Task Force (IOTF) criteria were used to define the following weight categories: underweight, healthy weight, overweight, obese (17). Any values out with five $z$ scores of the mean were excluded as presumed spurious results.

\section{Data Linkage:}

The method of conception of births occurring between 1997 and 2012 were linked to height and weight measurements at age 5 collected between 2002 and 2017 using the Community health Index (CHI) number. The $\mathrm{CHI}$ is a unique number given to each individual in Scotland. The AFCD has $\mathrm{CHI}$ number for women, STONES has $\mathrm{CHI}$ number for children and AMND has both the $\mathrm{CHI}$ number of mothers and offspring. The files were linked using $\mathrm{CHI}$ numbers in the National Safe Haven (18), this is a virtual private network where researcher can access linked and anonymised data but cannot print off results or export files.

\section{Ethical Approval}

Ethical approval was granted by the National Health Services (NHS) Grampian Research and Development Department (NHSG R \& D) (15/NS/0045), and the study was approved by the relevant Caldicott guardians.

\section{Statistical Analysis}


General linear models were used to compare cross sectional differences in fetal, newborn and maternal age, parity, weight, height, smoking status, socioeconomic status and offspring sex. Multilevel models (MLM) were used to describe longitudinal change in z scores for measurements in fetuses, new born and at five years of age between the three groups adjusting for the variables previously described. Only fetal measurements which were different in cross-sectional analyses were included in the longitudinal model. The MLM first explored whether when all measurements were considered collectively they differed between the three groups. A time variable was then added (10=first trimester, $20=$ second trimester, $30=$ third trimester, $40=$ birth and $286=$ five years) and an interaction term between time and measurement was created to determine whether differences in measurements between groups changed over time. Data analysis was completed using IBM SPSS (Statistical Package for the Social Sciences, SPS Inc., Chicago, IL, USA) version 24 for Windows. A statistical significance level of 0.05 was used for all comparisons.

\section{RESULTS}

\section{Study participants}

Data were available in 576 individuals conceived by fresh ET, 179 conceived by FET and 65,683 after NC. There were 45 blastocyst transfers among the IVF conceptions. Table 1 presents characteristics of mothers in these three groups. When compared to the fresh ET and FET groups, mothers in the NC group were significantly younger $(p<0.001)$, more likely to smoke $(p<0.001)$, more likely to come from the most deprived communities $(p<0.001)$, to be shorter $(p=0.003)$ and to have had a previous pregnancy $(p<0.001)$, but were comparable in weight body mass index and weight category. There was no significant difference in characteristics between mothers in the fresh ET and FET groups. Figure 1 presents details of the numbers of individuals where measurements were available.

\section{Cross sectional comparison of offspring}

Fetal measurements in antenatal period 
Summary of results for fetal measurements from cross sectional analyses adjusting for deprivation,

\section{Second trimester.}

Second trimester measurements were made at a mean (SD) gestation of 20.0 (1.5) weeks. Conception after IVF/ICSI was associated with a larger BPD when compared to NC, and this difference was seen when both fresh ET $(p<0.001)$ and FET ( $p=0.018)$ were individually compared with NC. There was no significant difference between the fresh ET and FET for BPD z score values. The FL was larger in conceptions as a result of FET compared to NC ( $p=0.019)$, and there was a trend which approached significance for a difference in FL between FET and fresh ET $(P=0.056)$, table 2.

\section{Third trimester}

Third trimester measurements were taken at a mean (SD) gestational age of 33.6 (3.0) weeks. There was no difference in any fetal measurements between any groups, table 2.

\section{Birth measurements}

Table 2 shows absolute measurements at birth and the relative differences with adjustment for deprivation, maternal smoking, a maternal identifier, offspring sex, maternal age, height and gestation at delivery. The different characteristics of mothers in the NC compared to fresh ET and FET groups meant that the differences between absolute measurements were of a notably different magnitude compared to adjusted differences. The proportion of babies born with low birth weight 
were similar in all three groups, but a significantly higher proportion of babies were of high birth weight ( $>4 \mathrm{~kg}$ ) in FET group ( $22 \%$ FET vs. $13 \%$ fresh ET and $13 \%$ NC $p=0.003$ ).

The mean $\mathrm{z}$ scores for birth weight and OFC differed between groups. Babies born following fresh ET were lighter at birth compared to both NC $(p<0.001)$ and FET $(p=0.002)$, and there was no difference in birth weight $\mathrm{z}$ scores between FET and NC, table 2. Differences in OFC between groups at birth followed a similar pattern to birth weight, and those born after fresh ET had smaller heads compared to NC $(p=0.009)$ and FET ( $p=0.019)$ with there being no difference in OFC between FET and NC groups, table 2. There were no differences in mean crown heel length.

\section{Measurement at age five years}

Table 2 shows results for the measurements at school entry between the groups adjusted for deprivation, maternal smoking, a maternal identifier, offspring sex, maternal age and age. Additionally, the analyses included the corresponding maternal anthropometric measurements e.g. for child height, maternal height was also included. Mean age at assessment was similar in all three groups at 5.6 years. Children conceived after fresh ET were heavier compared to the NC group ( $p$ 0.04), table 2 , and there was no difference in the mean weight between children conceived by FET compared to NC or between fresh ET and FET. There were no differences in height, BMI or weight category at 5 years in any of the comparisons between the three groups.

\section{Longitudinal analysis}

Longitudinal relationships between the following combination of anthropometric measurements were considered: $z$ scores of CRL in the first trimester and BPD in the second and third trimesters, birth weight and weight at five years. The differences between FET and NC and fresh ET and NC in the cross sectional analyses (table 2 ) were seen in the longitudinal model for antenatal measurements of CRL and BPD, figure 2 and Supplemental table 1. The reduced weight at birth and increased weight at five years among those conceived by fresh ET relative to NC was not significant in the longitudinal model, figure 2 and Supplemental table 1 . The associations between method of 
conception and longitudinal measurements were not substantially changed when the data from the third trimester were excluded from the analysis, supplemental table 1. When measurements were compared between individuals conceived by fresh ET and FET, the only significant difference was at birth (fresh ET lighter by a mean 0.25 z scores [95\% Cl 0.09, 0.44] p=0.007), supplemental table 2 .

\section{DISCUSSION}

\section{Principal findings:}

This study used routinely collected data to describe antenatal and postnatal growth of individuals conceived by IVF and after natural conception. It showed that individuals conceived after FET were larger in the second trimester than those conceived by NC, but this difference was not apparent at third trimesters, birth and five years. Conception after fresh ET was associated with a more erratic growth trajectory, initially larger than NC in first and second trimester and trend for being smaller at birth. The cross sectional analysis suggested a trend which was of borderline significance for children conceived by fresh ET to be heavier than NC at five years, but the longitudinal model (which considered previous growth trajectory) found no significant difference in weight between fresh ET and NC.

\section{Strengths}

To best of our knowledge this is the first study to report on antenatal ultrasound measurements, comparing NC with fresh ET and FET. We were also able to link maternal characteristics (including method of conception and height and weight) to offspring weight at five years in a relatively large number of individuals. Hence, we can determine growth trajectories from before and after birth in a large population and adjust for many confounders.

\section{Limitations}

The data are from a single geographical area and our results may not be replicated in other regions. A second limitation is that relatively small numbers of individuals conceived by IVF (especially by FET), and this may mean that some of the analyses were underpowered (e.g. the EFW analysis in the 
second trimester). There were missing fetal ultrasound scan data (although birth measurements measured in the third trimester for obstetric indications meaning that results were available for a particularly small proportion of individuals meaning that our analysis at this gestation was underpowered. However the associations seen in the longitudinal analysis for the whole population did not change substantially when the analysis was repeated after excluding third trimester measurements. For example, although the magnitude of increased head size and femur length seen in the fresh ET and FET in the second trimester persisted into the third trimester the difference did not reach significance. An additional limitation to our study is that differences in methods to ascertain gestation are different between IVF and NC groups and this may explain the different outcomes. For IVF, 14 days are added from the day of fertilisation to derive the date of last menstrual period (LMP) but for NC the interval between LMP and fertilisation is not always 14 days; we believe that this is unlikely to be a major issue since for NC the interval between LMP and fertilisation may be less than or greater than 14 days and on a whole population basis likely to be close to 14 days overall. There were very few IVF conceptions after blastocyst transfer and it is well known from the literature that there are differences in birthweight in pregnancies as a result of cleavage and blastocyst transfer. A higher proportion of embryo transfers are now done at blastocyst stage than the time period in which data for current study were collected. Future research (ideally in prospective studies) should compare different stages of embryo transfer to offspring weight. A further limitation is that we did not include paternal anthropometric measurements in our analysis, and this absence is likely to weaken the associations we describe and not strengthen them. Finally, we had no data between birth and at school entry, so we don't know how the weight trajectory was between these two times intervals (birth and 5 years).

\section{Comparison with other studies}

Our findings are consistent with some other, but not all studies. There is less consistency for anthropometric measurements in childhood across groups stratified by natural conception and 
IVF/ICSI without stratification for fresh ET and FET $(8,9,19-21)$. For example a study by Sutcliffe et stratifying for fresh ET and FET. A study of 69 children conceived by IVF/ICSI found a 0.5 standard deviation score increased in height at six years compared to those conceived by NC (8). Several studies have reported on childhood measurements after IVF/ICSI with stratification for fresh ET and FET (10, 22-24). Green et al. (22) report that conception by fresh ET was associated with increased height in prepubertal children. Knoester et al. (23) found no difference in mean weight at 5-8 years in children conceived by fresh ET and natural conception and Ainsworth et al. (24) also found no difference in weight, height and BMI measurements of five year olds between fresh ET and FET. A limitation of the studies by Green, Knoester and Ainsworth (22-24) is that the number of individuals conceived by IVF/ICSI was typically less than 100. A data linkage study involving 5200 children conceived by IVF and 20,800 by NC (10) found that babies born from fresh embryo transfer were lighter at birth and in the first few weeks of life, but this difference was not present at school age (aged 4-7 years), compared to peers conceived naturally or by FET. In contrast with our study, the study by Hann et al. (10) did not have data on antenatal growth and in the absence of a unique identifier, data were linked between mother and child using probabilistic matching. The study by Hann et al. (10) did not have maternal anthropometric measurements available and this may have reduced the ability of the analysis to detect differences in offspring anthropometric measurements in childhood, this limitation did not affect our analysis which is nonetheless consistent with Hann et al. (10) The different findings for weight difference at birth and at age five years between fresh ET and NC in cross sectional and longitudinal models suggests that future analyses should consider earlier measurements when exploring differences in anthropometric measurements at a given point in time.

The mechanism where IVF /ICSI methodology may cause abnormal growth is unclear (25), and epigenetic mechanisms may be important to many possible pathways to increased or reduced 
anthropometric measurements. For example, the hyperstimulation of the ovary, constituents of abnormal epigenetic changes. Periconception conditions have been associated with differences in birthweight in a number of studies, e.g. increased birth weight after implantation at the blastocyst stage compared to embryo culture $(26,27)$.

\section{Implications for clinical practice}

Our results provide reassurance for pregnancies conceived as a result of frozen embryo transfer since in the cross sectional and longitudinal models we only observed difference in size relative to NC only in the second trimester. In contrast in the cross sectional and longitudinal models, individuals conceived by fresh ET had a different growth trajectory to NC which in the cross sectional model persisted at birth and five years, and as low birth weight and post-natal catch up growth are independent risk factors for non-communicable diseases over life course, (28), individuals conceived after fresh ET may be at increased risk for conditions such as hypertension, type II diabetes and coronary artery disease.

\section{Implications for future research}

As our results are is limited by their historical nature, variable time for ultrasound and small numbers, a prospective data collection for pregnancies conceived as a result of fresh and frozen embryo transfer in both antenatal and post-natal period is needed to provide a definite answer. It is currently unknown what alters fetal and child growth trajectories for children conceived through IVF/ICSI, hence further observational and mechanistic studies are needed.

\section{CONCLUSION}

We have used the population of North East Scotland to explore the relationship between different IVF methods and associations with offspring weight. Our results support the use of FET over fresh ET, since the latter was associated with variable growth trajectory up to birth although the clinical implications of this differences are unknown. Larger prospective studies or follow up data from existing randomised trials are needed to provide a definitive answer. 


\section{ACKNOWLEDGEMENTS}

We thank Professor Siladitya Bhattacharya for his comment and suggestions made at the very start of this project.

\section{AUTHOR'S ROLES}

ST and AM conceived the idea. ST, EM and LA undertook the data preparation and analysis. SD and ST wrote the first draft of the manuscript. All authors made a meaningful contribution to the final manuscript.

\section{FUNDING}

The study was funded by the FARR Institute. 
1. Bhattacharya S, Porter M, Amalraj E, Templeton A, Hamilton M, Lee AJ, et al. The epidemiology of infertility in the North East of Scotland. Human Reproduction 2009;24:3096-107.

2. Jackson RA, Gibson KA, Wu YW, Croughan MS. Perinatal outcomes in singletons following in vitro fertilization: a meta-analysis. Obstetrics \& Gynecology 2004;103:551-63.

3. Pinborg A, Henningsen AA, Loft A, Malchau SS, Forman J, Andersen AN. Large baby syndrome in singletons born after frozen embryo transfer (FET): is it due to maternal factors or the cryotechnique?. Human Reproduction 2014;29:618-27.

4. Pandey S, Shetty A, Hamilton M, Bhattacharya S, Maheshwari A. Obstetric and perinatal outcomes in singleton pregnancies resulting from IVF/ICSI: a systematic review and meta-analysis. humupd 2012;18:485-503.

5. Pelkonen S, Koivunen R, Gissler M, Nuojua-Huttunen S, Suikkari A, Hyden-Granskog C, et al. Perinatal outcome of children born after frozen and fresh embryo transfer: the Finnish cohort study 1995-2006. Human Reproduction 2010;25:914-23.

6. Maheshwari A, Raja EA, Bhattacharya S. Obstetric and perinatal outcomes after either fresh or thawed frozen embryo transfer: an analysis of 112,432 singleton pregnancies recorded in the Human Fertilisation and Embryology Authority anonymized dataset. Fertility \& Sterility 2016;106:1703-8.

7. Berntsen S, Pinborg A. Large for gestational age and macrosomia in singletons born after frozen/thawed embryo transfer (FET) in assisted reproductive technology (ART). Birth Defects Research 2018;110:630-43.

8. Miles HL, Hofman PL, Peek J, Harris M, Wilson D, Robinson EM, et al. In vitro fertilization improves childhood growth and metabolism. Journal of Clinical Endocrinology \& Metabolism 2007;92:3441-5.

9. Sutcliffe AG, Melhuish E, Barnes J, Gardiner J. Health and development of children born after assisted reproductive technology and sub-fertility compared to naturally conceived children: data from a national study. Pediatric Reports 2014;6:5118.

10. Hann M, Roberts SA, D'Souza SW, Clayton P, Macklon N, Brison DR. The growth of assisted reproductive treatment-conceived children from birth to 5 years: a national cohort study. BMC Medicine 2018;16:224.

11. Maheshwari A, Scotland G, Bell J, McTavish A, Hamilton M, Bhattacharya S. The direct health services costs of providing assisted reproduction services in overweight or obese women: a retrospective cross-sectional analysis. Hum Reprod 2009;24:633-9.

12. Ayorinde AA, Wilde K, Lemon J, Campbell D, Bhattacharya S. Data Resource Profile: The Aberdeen Maternity and Neonatal Databank (AMND). Int J Epidemiol 2016;45:389-94.

13. Carstairs V, Morris R. Deprivation and health in Scotland. Health Bull 1990;48:162-75.

14. Hadlock FP, Harrist RB, Carpenter RJ, Deter RL, Park SK. Sonographic estimation of fetal weight. The value of femur length in addition to head and abdomen measurements. Radiology 1984;150:535-40. 
15. Cantonwine DE, Ferguson KK, Mukherjee B, Chen Y, Smith NA, Robinson JN, et al. Utilizing Longitudinal Measures of Fetal Growth to Create a Standard Method to Assess the Impacts of Maternal Disease and Environmental Exposure. PLoS ONE [Electronic Resource] 2016;11:e0146532.

16. Cole TJ, Freeman JV, Preece MA. Body mass index reference curves for the UK, 1990. Arch Dis Child 1995;73:25-9.

17. Cole TJ, Bellizzi MC, Flegal KM, Dietz WH. Establishing a standard definition for child overweight and obesity worldwide: international survey. BMJ 2000;320:1240-3.

18. Public Health Scotland. Use of the National Safe Haven. Available at https://www.isdscotland.org/Products-and-Services/EDRIS/Use-of-the-National-Safe-Haven/. Accessed May 152020.

19. Ceelen M, van Weissenbruch MM, Prein J, Smit JJ, Vermeiden JPW, Spreeuwenberg M, et al. Growth during infancy and early childhood in relation to blood pressure and body fat measures at age 8-18 years of IVF children and spontaneously conceived controls born to subfertile parents. Human Reproduction 2009;24:2788-95.

20. Kai CM, Main KM, Andersen AN, Loft A, Chellakooty M, Skakkebaek NE, et al. Serum insulin-like growth factor-I (IGF-I) and growth in children born after assisted reproduction. Journal of Clinical Endocrinology \& Metabolism 2006;91:4352-60.

21. Meddeb L, Pauly V, Boyer P, Montjean D, Devictor B, Curel L, et al. Longitudinal growth of French singleton children born after in vitro fertilization and intracytoplasmic sperm injection. Body mass index up to 5 years of age. Rev Epidemiol Sante Publique 2017;65:197-208.

22. Green MP, Mouat F, Miles HL, Hopkins SA, Derraik JG, Hofman PL, et al. Phenotypic differences in children conceived from fresh and thawed embryos in in vitro fertilization compared with naturally conceived children. Fertil Steril 2013;99:1898-904.

23. Knoester M, Helmerhorst FM, Vandenbroucke JP, van der Westerlaken LA, Walther FJ, Veen $\mathrm{S}$, et al. Perinatal outcome, health, growth, and medical care utilization of 5- to 8-year-old intracytoplasmic sperm injection singletons. Fertil Steril 2008;89:1133-46.

24. Ainsworth AJ, Wyatt MA, Hathcock M, Borowski K, Coddington CC. The effect of fresh vs. frozen embryo transfer on neonatal and pediatric weight and weight gain trajectory. Fertil Steril 2018;109:e13-4.

25. Pereira N, Petrini AC, Hancock KL, Rosenwaks Z. Fresh or Frozen Embryo Transfer in In Vitro Fertilization: An Update. Clinical Obstetrics \& Gynecology 2019;62:293-9.

26. Wikland M, Hardarson T, Hillensjo T, Westin C, Westlander G, Wood M, et al. Obstetric outcomes after transfer of vitrified blastocysts. Human Reproduction 2010;25:1699-707.

27. Zhang J, Wang $Y$, Liu $H$, Mao X, Chen $Q$, Fan $Y$, et al. Effect of in vitro culture period on birth weight after vitrified-warmed transfer cycles: analysis of 4,201 singleton newborns. Fertility \& Sterility 2019;111:97-104.

28. Singhal A. Long-Term Adverse Effects of Early Growth Acceleration or Catch-Up Growth. Ann Nutr Metab 2017;70:236-40. 


\section{FIGURE LEGENDS}

Figure 1. Flowchart showing number of study participants for whom measurements were available at various stages of gestation, at birth and at five years of age.

Figure 2. This compares mean (circle) standardised anthropometric measurements and $95 \%$ confidence intervals (vertical line) in the first (T1), second (T2) and third (T3) trimesters, at birth and at age five years (5y) between individuals conceived by fresh embryo transfer (fresh ET) or frozen embryo transfer (FET) relative to those who had natural conception. The fetal measurements were crown rump length (CRL) and biparietal diameter (BPD). The mean and $95 \% \mathrm{Cl}$ are from a longitudinal model. The measurements included in the longitudinal model were chosen from cross sectional models. ${ }^{*} p<0.01$ and $t<0.05$ for comparison with natural conception. 
Table 1. Characteristics of mothers included in the analysis. SD=standard deviation. ${ }^{*} p<0.05$ compared with Fresh embryo transfer, $\uparrow p<0.001$ and $\neq p=0.003$ compared to the IVF groups.

\begin{tabular}{|c|c|c|c|c|}
\hline \multirow{2}{*}{\multicolumn{2}{|c|}{ Mean maternal age (SD), y }} & $\begin{array}{l}\text { Fresh Embryo } \\
\text { Transfer (fresh ET) }\end{array}$ & $\begin{array}{l}\text { Frozen thawed embryo } \\
\text { transfer (FET) }\end{array}$ & $\begin{array}{l}\text { Natural conception } \\
\text { (NC) }\end{array}$ \\
\hline & & $34.3(4.0) n=576$ & $35.0(4.0) n=179 *$ & $\begin{array}{c}29.2(5.7)^{\dagger} \\
n=65,683\end{array}$ \\
\hline \multicolumn{2}{|c|}{$\%$ maternal smoking, $(\mathrm{n})$} & $6 \%(33)$ & $7 \%(11)$ & $21 \%(12,473)$ \\
\hline \multicolumn{2}{|c|}{ Mean maternal height (SD), cm } & $165(6)$ & $165(6)$ & $164(7) \ddagger$ \\
\hline \multicolumn{2}{|c|}{ Mean maternal weight (SD), kg } & $69(12)$ & $69(13)$ & $69(15)$ \\
\hline \multicolumn{2}{|c|}{$\begin{array}{l}\text { Mean maternal body mass index (SD), } \\
\mathrm{kg} /{ }^{2}\end{array}$} & $25.4(4.3)$ & $25.4(4.6)$ & $25.7(5.4)$ \\
\hline \multirow{4}{*}{$\begin{array}{l}\text { Maternal weight } \\
\text { category }\end{array}$} & Underweight & $1 \%(3)$ & 0 & $2 \%(36)$ \\
\hline & Healthy weight & $77 \%(162)$ & $79 \%(73)$ & $77 \%(20,688)$ \\
\hline & Overweight & $11 \%(24)$ & $8 \%(7)$ & $12 \%(3,214)$ \\
\hline & Obese & $10 \%(22)$ & $13 \%(12)$ & $10 \%(2,712)$ \\
\hline \multirow{4}{*}{ Parity } & 0 & $80 \%(463)$ & $56 \%(100)^{*}$ & $49 \%(31,839)+$ \\
\hline & 1 & $17 \%(98)$ & $30 \%(71)$ & $35 \%(22,917)$ \\
\hline & 2 & $2 \%(8)$ & $4 \%(7)$ & $12 \%(7,534)$ \\
\hline & $\geq 2$ & & & $5 \%(3,318)$ \\
\hline \multirow{6}{*}{$\begin{array}{l}\text { Socioeconomic } \\
\text { status (Carstairs } \\
\text { index) }\end{array}$} & Least deprived & $33 \%(1810)$ & $34 \%(58)$ & $22 \%(13,454)+$ \\
\hline & 2 & $33 \%(179)$ & $32 \%(55)$ & $29 \%(18,130)$ \\
\hline & 3 & $17 \%(91)$ & $21 \%(35)$ & $17 \%(10,862)$ \\
\hline & 4 & $12 \%(66)$ & $9 \%(16)$ & $18 \%(10,955)$ \\
\hline & 5 & $2 \%(11)$ & & $5 \%(3,085)$ \\
\hline & Most deprived & $3 \%(17)$ & $3 \%(5)$ & $10 \%(6,190)$ \\
\hline
\end{tabular}


Table 2. Fetal, Birth and Age 5 measurements. *including adjustment for deprivation, maternal smoking, a maternal identifier, offspring sex, maternal age, height and gestation in days at scan gestation at delivery and age. Additionally, the analysis included the corresponding maternal anthropometric measurements, e.g. for child height, maternal height was also included. SD= standard deviation, NS=not significant.

\begin{tabular}{|c|c|c|c|c|c|c|c|}
\hline & & $\begin{array}{c}\text { Fresh Embryo } \\
\text { Transfer } \\
\text { (fresh ET) }\end{array}$ & $\begin{array}{l}\text { Frozen embryo } \\
\text { transfer } \\
\text { (FET) }\end{array}$ & $\begin{array}{c}\text { Natural conception } \\
\text { (NC) }\end{array}$ & $\begin{array}{c}\text { Mean difference*, } \\
95 \% \text { Confidence } \\
\text { Interval ( } \mathrm{p} \text { value) } \\
\text { fresh ET vs NC }\end{array}$ & $\begin{array}{c}\text { Mean difference*, 95\% } \\
\text { Confidence Interval ( } p \\
\text { value) } \\
\text { FET vs NC }\end{array}$ & $\begin{array}{c}\text { Mean difference*, } \\
95 \% \text { Confidence } \\
\text { Interval ( } p \text { value) } \\
\text { FET vs fresh ET }\end{array}$ \\
\hline \multicolumn{2}{|c|}{ Male offspring } & $\begin{array}{c}55 \% \\
(317 / 576)\end{array}$ & $\begin{array}{c}48 \% \\
(86 / 179)\end{array}$ & $\begin{array}{c}51 \% \\
(33,794 / 65,907)\end{array}$ & NS & NS & NS \\
\hline \multicolumn{2}{|c|}{$\begin{array}{l}\text { Mean first trimester CRL z score } \\
\text { (SD) }\end{array}$} & $\begin{array}{c}0.30(0.89) \\
n=135\end{array}$ & $\begin{array}{c}0.30(0.81) \\
n=61\end{array}$ & $\begin{array}{c}0(1.00) \\
n=15,053\end{array}$ & $\begin{array}{c}0.21[0.03,0.39] \\
p=0.024\end{array}$ & $\begin{array}{c}0.15[-0.11,0.41] \\
p=0.250\end{array}$ & $\begin{array}{c}-0.05[-0.37,0.26] \\
p=0.160\end{array}$ \\
\hline \multicolumn{2}{|c|}{$\begin{array}{l}\text { Mean second trimester BPD z } \\
\text { score (SD) }\end{array}$} & $\begin{array}{c}0.36(0.96) \\
n=151\end{array}$ & $\begin{array}{c}0.37(0.80) \\
n=66\end{array}$ & $\begin{array}{c}-0.01(1.00) \\
n=17,735\end{array}$ & $\begin{array}{c}0.32[0.16,0.49] \\
p<0.001\end{array}$ & $\begin{array}{c}0.30[0.05,0.55] \\
p=0.018\end{array}$ & $\begin{array}{c}-0.03[-0.32,0.27] \\
p=0.864\end{array}$ \\
\hline \multicolumn{2}{|c|}{$\begin{array}{l}\text { Mean second trimester FL z score } \\
\text { (SD) }\end{array}$} & $\begin{array}{c}0.09(1.09) \\
n=146\end{array}$ & $\begin{array}{c}0.35(0.77) \\
n=65\end{array}$ & $\begin{array}{l}0.0 \quad(1.0) \\
n=17,286\end{array}$ & $\begin{array}{c}0.01[-0.17,0.18] \\
p=0.952\end{array}$ & $\begin{array}{c}0.30[0.05,0.55] \\
p=0.019\end{array}$ & $\begin{array}{c}0.30[-0.01,0.60] \\
p=0.056\end{array}$ \\
\hline \multicolumn{2}{|c|}{$\begin{array}{l}\text { Mean second trimester EFW z } \\
\text { score (SD) }\end{array}$} & $\begin{array}{c}0.26(1.32) \\
n=79\end{array}$ & $\begin{array}{c}0.59(1.25) \\
n=30\end{array}$ & $\begin{array}{c}0(0.99) \\
n=10.923\end{array}$ & $\begin{array}{c}0.13[-0.08,0.33] \\
p=0.212\end{array}$ & $\begin{array}{c}0.23[-0.10,0.56] \\
p=0.166\end{array}$ & $\begin{array}{c}0.10[-0.28,0.48] \\
p=0.597\end{array}$ \\
\hline \multicolumn{2}{|c|}{$\begin{array}{l}\text { Mean third trimester BPD z score } \\
\text { (SD) }\end{array}$} & $\begin{array}{c}0.27(1.19) \\
n=50\end{array}$ & $\begin{array}{c}0.12(1.01) \\
n=23\end{array}$ & $\begin{array}{c}0(1.0) \\
n=6,872\end{array}$ & $\begin{array}{c}0.19[-0.09,0.48] \\
p=0.177\end{array}$ & $\begin{array}{c}-0.02[-0.44,0.40] \\
p=0.936\end{array}$ & $\begin{array}{c}-0.21[-0.71,0.29] \\
p=0.411\end{array}$ \\
\hline \multicolumn{2}{|c|}{$\begin{array}{l}\text { Mean third trimester FL z score } \\
\text { (SD) }\end{array}$} & $\begin{array}{c}0.04(0.95) \\
n=47\end{array}$ & $\begin{array}{c}0.37((1.02) \\
n=23\end{array}$ & $\begin{array}{r}0(1.0) \\
n=6535\end{array}$ & $\begin{array}{c}-0.14[-0.43,0.15] \\
p=0.336\end{array}$ & $\begin{array}{c}0.22[-0.21,0.64] \\
p=0.310\end{array}$ & $\begin{array}{c}0.36[-0.15,0.87] \\
p=0.166\end{array}$ \\
\hline \multicolumn{2}{|c|}{$\begin{array}{l}\text { Mean third trimester EFW z score } \\
\text { (SD) }\end{array}$} & $\begin{array}{c}0.25(1.15) \\
n=46\end{array}$ & $\begin{array}{c}0.32(1.09) \\
n=21\end{array}$ & $\begin{array}{c}0(1.0) \\
n=6,347\end{array}$ & $\begin{array}{c}0.09[-0.21,0.38] \\
p=0.558\end{array}$ & $\begin{array}{c}0.20[-0.25,0.64] \\
p=0.385\end{array}$ & $\begin{array}{c}0.11[-0.42,0.64] \\
p=0.684\end{array}$ \\
\hline \multicolumn{2}{|c|}{ Mean birth weight (SD), g } & $\begin{array}{c}3335(664) \\
n=576\end{array}$ & $\begin{array}{c}3473(689) \\
n=179\end{array}$ & $\begin{array}{c}3390(621) \\
n=65,674\end{array}$ & $\begin{array}{c}-95[-134,-57] \\
p<0.001\end{array}$ & $\begin{array}{c}29[-41,98] \\
p=0.418\end{array}$ & $\begin{array}{c}124[45,203] \\
p=0.002\end{array}$ \\
\hline \multirow{2}{*}{$\begin{array}{l}\text { Birth } \\
\text { weight } \\
\text { category }\end{array}$} & Birth weight <2.5kg & $7 \%(42)$ & $7 \%(13)$ & $7 \%(4322)$ & NS & NS & NS \\
\hline & Birth weight $>4 \mathrm{~kg}$ & $13 \%(74)$ & $22 \%(39)$ & $13 \%(8838)$ & NS & NS & NS \\
\hline \multicolumn{2}{|c|}{ Mean birth weight z score (SD) } & $\begin{array}{c}-0.04(1.07) \\
n=576\end{array}$ & $\begin{array}{c}0.20(1.04) \\
n=178\end{array}$ & $\begin{array}{c}0(1.0) \\
n=65,674\end{array}$ & $\begin{array}{c}-0.21[-0.29,-0.12] \\
p<0.001\end{array}$ & $\begin{array}{c}0.06[-0.9,0.21] \\
p=0.418\end{array}$ & $\begin{array}{c}0.27[0.10,0.44] \\
p=0.002\end{array}$ \\
\hline \multicolumn{2}{|c|}{ Mean crown heel length (SD), cm } & $\begin{array}{c}49.6(3.3) \\
n=571\end{array}$ & $\begin{array}{c}49.9(3.1) \\
n=175\end{array}$ & $\begin{array}{l}49.6(3.1) \\
n=65,330\end{array}$ & $\begin{array}{c}-0.10[-0.29,0.08] \\
p=0.275\end{array}$ & $\begin{array}{c}-0.04[-0.38,0.29] \\
p=0.806\end{array}$ & $\begin{array}{c}0.06[-0.32,0.44] \\
p=0.751\end{array}$ \\
\hline
\end{tabular}




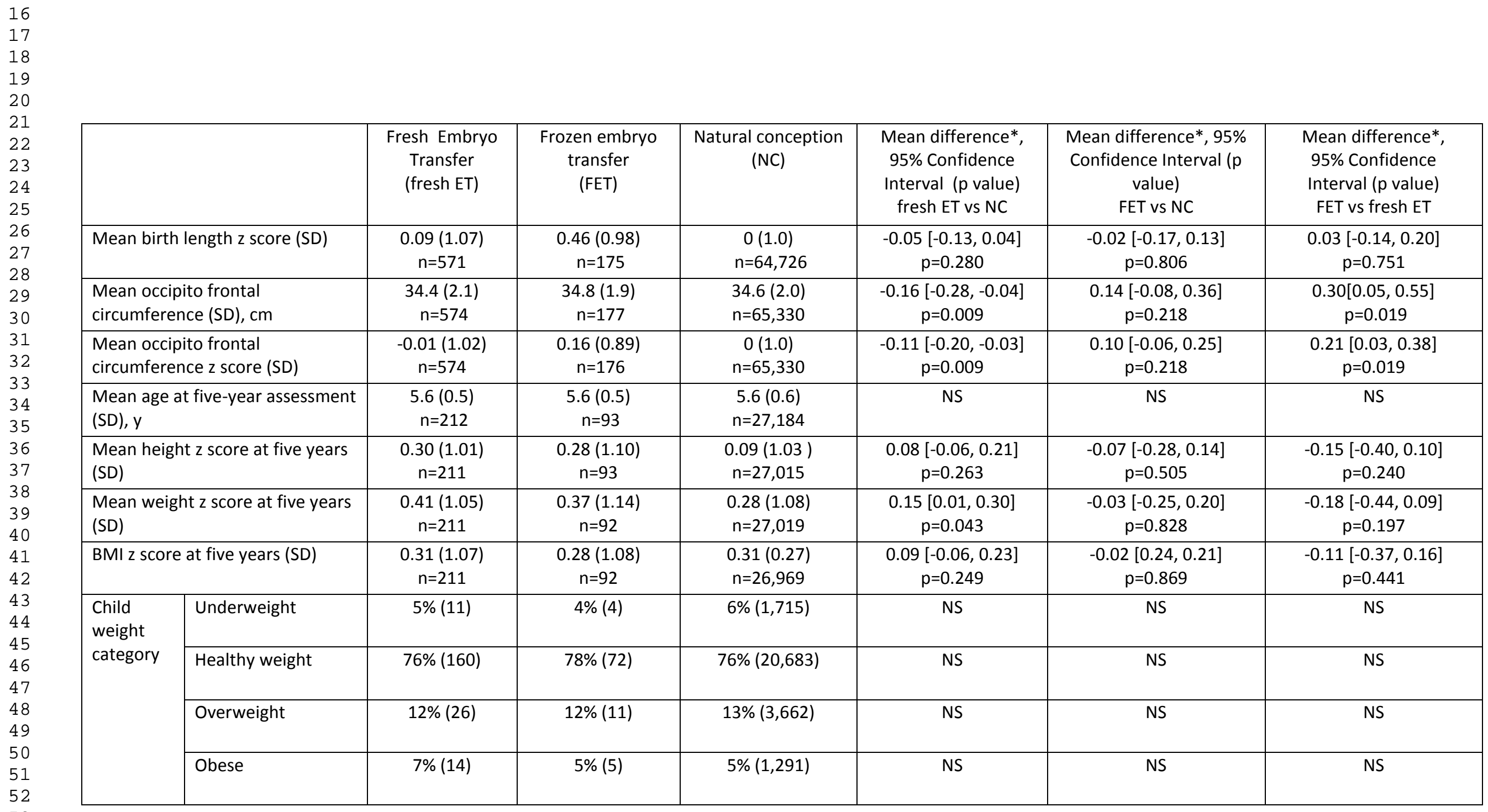




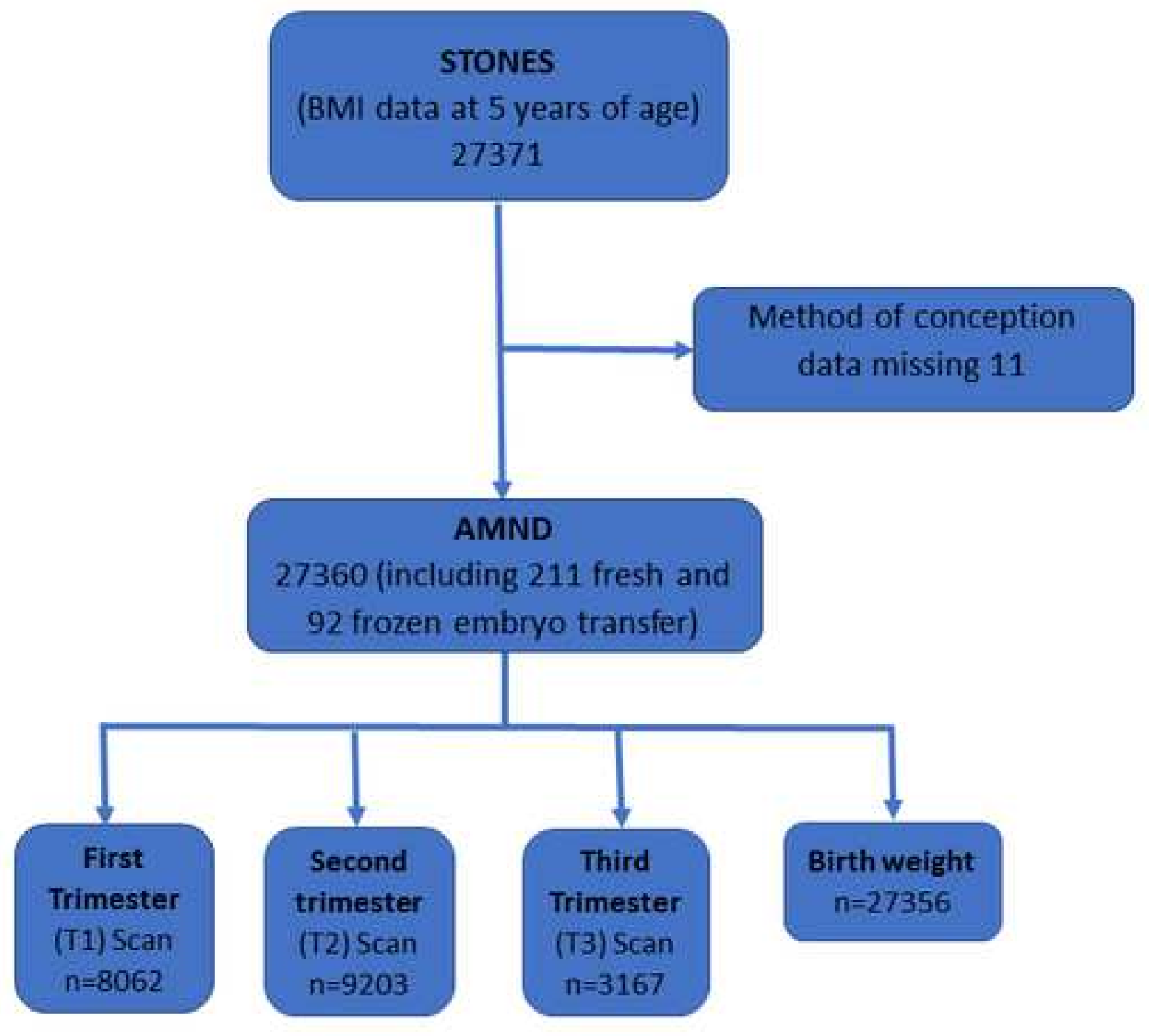




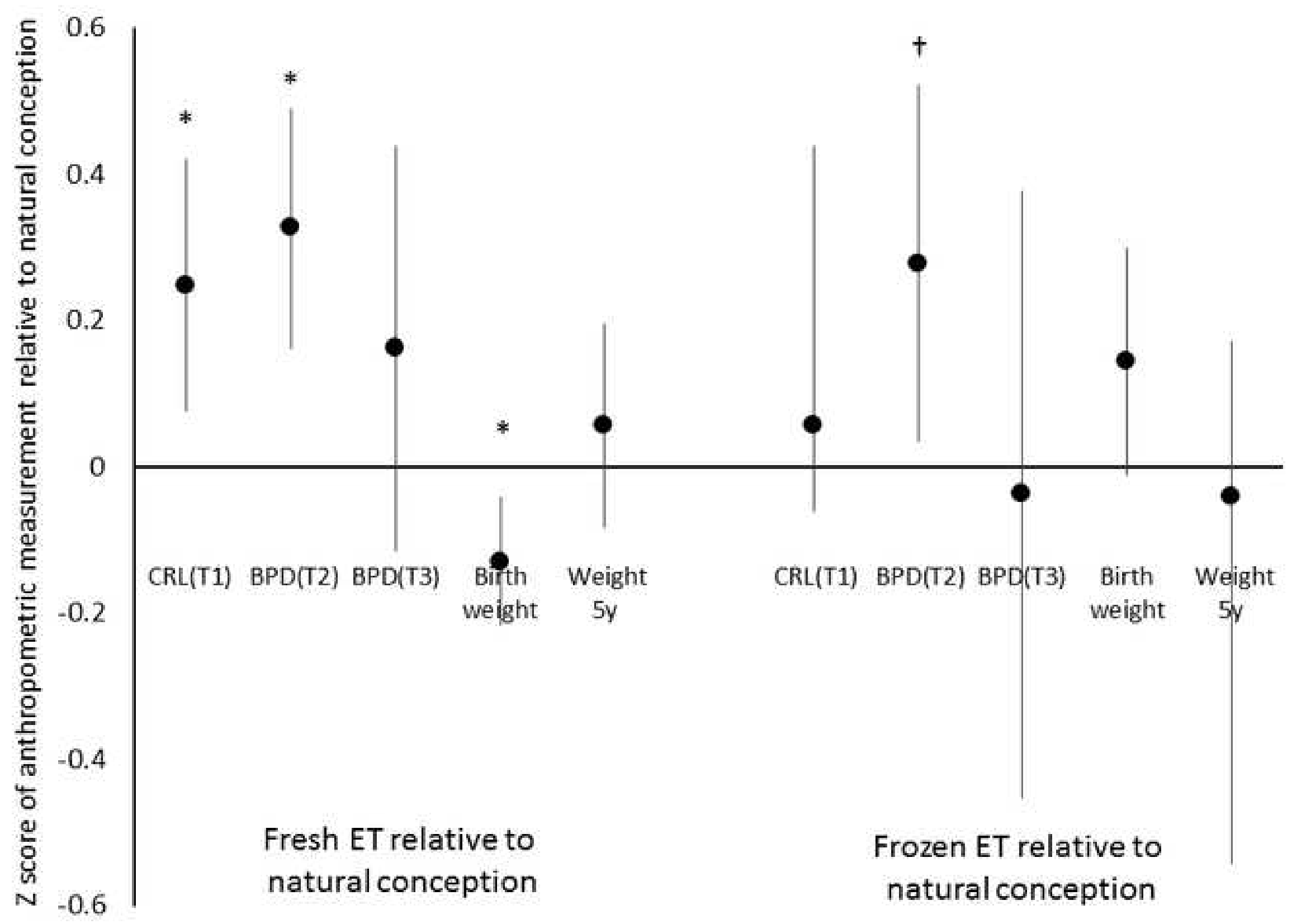


Supplemental Table 1. Differences from the longitudinal model which considered crown rump length (first trimester measurement), biparietal diameter (second and third trimester measurement), birth weight and weight at age five years and made comparisons between individuals conceived by fresh embryo transfer (fresh ET) or frozen embryo transfer (FET) relative to natural conception (NC).

\begin{tabular}{|c|c|c|}
\hline & $\begin{array}{c}\text { Fresh Embryo transfer } \\
\text { (fresh ET) } \\
\text { Mean difference } 95 \% \text { Confidence } \\
\text { Interval ( } p \text { value) }\end{array}$ & $\begin{array}{c}\text { Frozen Embryo Transfer } \\
\text { (FET) } \\
\text { Mean difference } 95 \% \text { Confidence } \\
\text { Interval ( } p \text { value) }\end{array}$ \\
\hline First trimester & $0.30[0.13,0.47] p=0.0006$ & $0.20[-0.05,0.45] p=0.120$ \\
\hline Second trimester & $\begin{array}{c}0.37[0.21,0.54] \\
p<0.001\end{array}$ & $0.29[0.04,0.53] p=0.0216$ \\
\hline Third trimester & $0.21[-0.07,0.49] p=0.135$ & $\begin{array}{c}-0.03[-0.45,0.38] \\
p=0.879\end{array}$ \\
\hline Birth & $-0.08[-0.17,0.00] p=0.062$ & $\begin{array}{c}0.15[-0.01,0.31] \\
p=0.059\end{array}$ \\
\hline Five years & $0.11[-0.03,0.25] p=0.132$ & $\begin{array}{c}-0.04[-0.25,0.18] \\
p=0.745\end{array}$ \\
\hline
\end{tabular}




\section{STROBE (Strengthening The Reporting of OBservational Studies in Epidemiology) Checklist}

A checklist of items that should be included in reports of observational studies. You must report the page number in your manuscript where you consider each of the items listed in this checklist. If you have not included this information, either revise your manuscript accordingly before submitting or note N/A.

Note: An Explanation and Elaboration article discusses each checklist item and gives methodological background and published examples of transparent reporting. The STROBE checklist is best used in conjunction with this article (freely available on the Web sites of PLoS Medicine at http://www.plosmedicine.org/, Annals of Internal Medicine at http://www.annals.org/, and Epidemiology at http://www.epidem.com/). Information on the STROBE Initiative is available at www.strobe-statement.org.

\begin{tabular}{|c|c|c|c|}
\hline Section and Item & $\begin{array}{l}\text { Item } \\
\text { No. }\end{array}$ & Recommendation & $\begin{array}{l}\text { Reported on } \\
\text { Page No. }\end{array}$ \\
\hline \multirow[t]{2}{*}{ Title and Abstract } & \multirow[t]{2}{*}{1} & $\begin{array}{l}\text { (a) Indicate the study's design with a commonly used term in the title or the } \\
\text { abstract }\end{array}$ & 2 \\
\hline & & $\begin{array}{l}\text { (b) Provide in the abstract an informative and balanced summary of what was } \\
\text { done and what was found }\end{array}$ & 2 \\
\hline \multicolumn{4}{|l|}{ Introduction } \\
\hline Background/Rationale & 2 & $\begin{array}{l}\text { Explain the scientific background and rationale for the investigation being } \\
\text { reported }\end{array}$ & 3 \\
\hline Objectives & 3 & State specific objectives, including any prespecified hypotheses & 3 \\
\hline \multicolumn{4}{|l|}{ Methods } \\
\hline Study Design & 4 & Present key elements of study design early in the paper & 4 \\
\hline Setting & 5 & $\begin{array}{l}\text { Describe the setting, locations, and relevant dates, including periods of } \\
\text { recruitment, exposure, follow-up, and data collection }\end{array}$ & 4,5 \\
\hline \multirow[t]{5}{*}{ Participants } & \multirow[t]{5}{*}{6} & $\begin{array}{l}\text { (a) Cohort study-Give the eligibility criteria, and the sources and methods of } \\
\text { selection of participants. Describe methods of follow-up }\end{array}$ & 4,5 \\
\hline & & $\begin{array}{l}\text { Case-control study-Give the eligibility criteria, and the sources and methods of } \\
\text { case ascertainment and control selection. Give the rationale for the choice of } \\
\text { cases and controls }\end{array}$ & \\
\hline & & $\begin{array}{l}\text { Cross-sectional study-Give the eligibility criteria, and the sources and methods of } \\
\text { selection of participants }\end{array}$ & \\
\hline & & $\begin{array}{l}\text { (b) Cohort study-For matched studies, give matching criteria and number of } \\
\text { exposed and unexposed }\end{array}$ & $\mathrm{N} / \mathrm{A}$ \\
\hline & & $\begin{array}{l}\text { Case-control study-For matched studies, give matching criteria and the number } \\
\text { of controls per case }\end{array}$ & \\
\hline Variables & 7 & $\begin{array}{l}\text { Clearly define all outcomes, exposures, predictors, potential confounders, and } \\
\text { effect modifiers. Give diagnostic criteria, if applicable }\end{array}$ & $4,5,6$ \\
\hline
\end{tabular}




\begin{tabular}{|c|c|c|c|}
\hline Section and Item & $\begin{array}{l}\text { Item } \\
\text { No. }\end{array}$ & Recommendation & $\begin{array}{c}\text { Reported on } \\
\text { Page No. }\end{array}$ \\
\hline $\begin{array}{l}\text { Data Sources/ } \\
\text { Measurement }\end{array}$ & $8^{*}$ & $\begin{array}{l}\text { For each variable of interest, give sources of data and details of methods of } \\
\text { assessment (measurement). Describe comparability of assessment methods if } \\
\text { there is more than one group }\end{array}$ & $4,5,6$ \\
\hline Bias & 9 & Describe any efforts to address potential sources of bias & 9 \\
\hline Study Size & 10 & Explain how the study size was arrived at & $\mid 4,5$ \\
\hline Quantitative Variables & 11 & $\begin{array}{l}\text { Explain how quantitative variables were handled in the analyses. If applicable, } \\
\text { describe which groupings were chosen and why }\end{array}$ & $\mid 6$ \\
\hline \multirow[t]{5}{*}{ Statistical Methods } & \multirow[t]{5}{*}{12} & $\begin{array}{l}\text { (a) Describe all statistical methods, including those used to control for } \\
\text { confounding }\end{array}$ & 6 \\
\hline & & (b) Describe any methods used to examine subgroups and interactions & 6 \\
\hline & & (c) Explain how missing data were addressed & 9 \\
\hline & & $\begin{array}{l}\text { (d) Cohort study-If applicable, explain how loss to follow-up was addressed } \\
\text { Case-control study-If applicable, explain how matching of cases and controls was } \\
\text { addressed } \\
\text { Cross-sectional study-If applicable, describe analytical methods taking account of } \\
\text { sampling strategy }\end{array}$ & \\
\hline & & (e) Describe any sensitivity analyses & \\
\hline \multicolumn{4}{|l|}{ Results } \\
\hline \multirow[t]{3}{*}{ Participants } & \multirow[t]{3}{*}{$13^{*}$} & $\begin{array}{l}\text { (a) Report numbers of individuals at each stage of study-eg numbers potentially } \\
\text { eligible, examined for eligibility, confirmed eligible, included in the study, } \\
\text { completing follow-up, and analysed }\end{array}$ & 6, Figure 1 \\
\hline & & (b) Give reasons for non-participation at each stage & 9 \\
\hline & & (c) Consider use of a flow diagram & Figure 1 \\
\hline \multirow[t]{3}{*}{ Descriptive Data } & \multirow[t]{3}{*}{$14^{*}$} & $\begin{array}{l}\text { (a) Give characteristics of study participants (eg demographic, clinical, social) and } \\
\text { information on exposures and potential confounders }\end{array}$ & 6, Table1 \\
\hline & & (b) Indicate number of participants with missing data for each variable of interest & \\
\hline & & (c) Cohort study-Summarise follow-up time (eg, average and total amount) & \\
\hline \multirow[t]{3}{*}{ Outcome Data } & \multirow[t]{3}{*}{$15^{*}$} & $\begin{array}{l}\text { Cohort study-Report numbers of outcome events or summary measures over } \\
\text { time }\end{array}$ & |Tablesl 1 and 2 \\
\hline & & $\begin{array}{l}\text { Case-control study-Report numbers in each exposure category, or summary } \\
\text { measures of exposure }\end{array}$ & \\
\hline & & Cross-sectional study-Report numbers of outcome events or summary measures & \\
\hline
\end{tabular}




\begin{tabular}{|c|c|c|c|}
\hline Section and Item & $\begin{array}{l}\text { Item } \\
\text { No. }\end{array}$ & Recommendation & $\begin{array}{l}\text { Reported on } \\
\text { Page No. }\end{array}$ \\
\hline \multirow[t]{3}{*}{ Main Results } & \multirow[t]{3}{*}{16} & $\begin{array}{l}\text { (a) Give unadjusted estimates and, if applicable, confounder-adjusted estimates } \\
\text { and their precision (eg, } 95 \% \text { confidence interval). Make clear which confounders } \\
\text { were adjusted for and why they were included }\end{array}$ & 6-9 \\
\hline & & (b) Report category boundaries when continuous variables were categorized & \\
\hline & & $\begin{array}{l}\text { (c) If relevant, consider translating estimates of relative risk into absolute risk for a } \\
\text { meaningful time period }\end{array}$ & \\
\hline Other Analyses & 17 & $\begin{array}{l}\text { Report other analyses done-eg analyses of subgroups and interactions, and } \\
\text { sensitivity analyses }\end{array}$ & 6 \\
\hline \multicolumn{4}{|l|}{ Discussion } \\
\hline Key Results & 18 & Summarise key results with reference to study objectives & 9 \\
\hline Limitations & 19 & $\begin{array}{l}\text { Discuss limitations of the study, taking into account sources of potential bias or } \\
\text { imprecision. Discuss both direction and magnitude of any potential bias }\end{array}$ & 9 \\
\hline Interpretation & 20 & $\begin{array}{l}\text { Give a cautious overall interpretation of results considering objectives, limitations, } \\
\text { multiplicity of analyses, results from similar studies, and other relevant evidence }\end{array}$ & 10,11 \\
\hline Generalisability & 21 & Discuss the generalisability (external validity) of the study results & 12 \\
\hline \multicolumn{4}{|l|}{ Other Information } \\
\hline Funding & 22 & $\begin{array}{l}\text { Give the source of funding and the role of the funders for the present study and, if } \\
\text { applicable, for the original study on which the present article is based }\end{array}$ & 13 \\
\hline
\end{tabular}

*Give information separately for cases and controls in case-control studies and, if applicable, for exposed and unexposed groups in cohort and cross-sectional studies.

Once you have completed this checklist, please save a copy and upload it as part of your submission. DO NOT include this checklist as part of the main manuscript document. It must be uploaded as a separate file. 


\section{Fertility and Sterility.}

\section{STATEMENT OF AUTHORSHIP}

Each author is required to submit a signed Statement of Authorship upon submission. This applies to all submission types including Editorials, Letters to the Editor, etc.

Date: 2nd March 2020

Manuscript \# (if available):

Manuscript title: Is conception by in vitro fertilisation associated with altered antenatal and postnatal growth trajectories?

Corresponding author: Steve Turner

Authors may either sign the same form or submit individually

I am an author on this submission, have adhered to all editorial policies for submission as described in the Information for Authors, attest to having met all authorship criteria, and disclosed all potential conflicts of interest for inclusion on the title page of the submission.

Signatures are required - typed signatures are unacceptable,

Typed or CLEARLY Printed Name:Steve Turner

Signature:

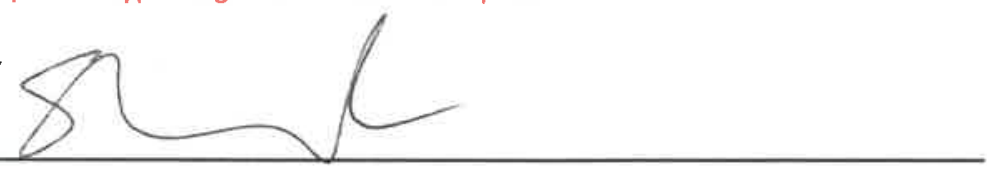

Typed or CLEARLY Printed Name:

Signature:

Typed or CLEARLY Printed Name:

Signature:

Typed or CLEARLY Printed Name:

Signature:

Typed or CLEARLY Printed Name:

Signature:

Typed or CLEARLY Printed Name:

Signature:

Typed or CLEARLY Printed Name:

Signature:

Typed or CLEARLY Printed Name:

Signature: 


\section{Fertility \\ and Sterility.}

\section{STATEMENT OF AUTHORSHIP}

Each author is required to submit a signed Statement of Authorship upon submission. This applies to all submission types including Editorials, Letters to the Editor, etc.

Date: $19.02 \cdot 20 \quad$ Manuscript \# (if available):

Manuscript title: Is c $\partial_{n c e p t i} \partial_{n}$ by in-vitr $\partial_{\text {fertilisati }} \partial_{n}$ ass $\partial_{\text {ciated }}$ with altered antenatal and $p \partial_{\text {stnatal gr }} \partial_{\text {wth traject }} \partial_{\text {ries? }}$

corresponding author: Eilidh Maclean

Authors may either sign the same form or submit individually

I am an author on this submission, have adhered to all editorial policies for submission as described in the Information for Authors, attest to having met all authorship criteria, and disclosed all potential conflicts of interest for inclusion on the title page of the submission.

Signatures are required - typed signatures are unacceptable.

Typed or CLEARLY Printed Name: EILIDH MACLEAN

Signature: EMadean

Typed or CLEARLY Printed Name:

Signature:

Typed or CLEARLY Printed Name:

Signature:

Typed or CLEARLY Printed Name:

Signature:

Typed or CLEARLY Printed Name:

Signature:

Typed or CLEARLY Printed Name:

Signature:

Typed or CLEARLY Printed Name:

Signature:

Typed or CLEARLY Printed Name:

Signature: 


\section{STATEMENT OF AUTHORSHIP}

Each author is required to submit a signed Statement of Authorship upon submission. This applies to all submission types including Editorials, Letters to the Editor, etc.

Date: $13 / 02 / 20 \quad$ Manuscript \# (if available):

Manuscript title:

Is conception by in-vitro fertilisation associated with altered antenatal and postnatal growth trajectories?

Corresponding author: Prof Steve Turner

Authors may either sign the same form or submit individually

I am an author on this submission, have adhered to all editorial policies for submission as described in the Information for Authors, attest to having met all authorship criteria, and disclosed all potential conflicts of interest for inclusion on the title page of the submission.

Signatures are required - typed signatures are unacceptable.

Typed or CLEARLY Printed Name: Smita Dick

Signature: SintaDick

Typed or CLEARLY Printed Name:

Signature:

Typed or CLEARLY Printed Name:

Signature:

Typed or CLEARLY Printed Name:

Signature:

Typed or CLEARLY Printed Name:

Signature:

Typed or CLEARLY Printed Name:

Signature:

Typed or CLEARLY Printed Name:

Signature:

Typed or CLEARLY Printed Name:

Signature: 


\section{STATEMENT OF AUTHORSHIP}

Each author is required to submit a signed Statement of Authorship upon submission. This applies to all submission types including Editorials, Letters to the Editor, etc.

Date: 14 th Feb 2020

Manuscript \# (if available):

Manuscript title: Is conception by in-vitro fertilisation associated with altered antenatal and postnatal growth trajectories?

Corresponding author:

Authors may either sign the same form or submit individually

I am an author on this submission, have adhered to all editorial policies for submission as described in the Information for Authors, attest to having met all authorship criteria, and disclosed all potential conflicts of interest for inclusion on the title page of the submission.

Signatures are required - typed signatures are unacceptable.

Typed or CLEARLY Printed Name: Dr Lorna Aucott

signature: loma AuctA

Typed or CLEARLY Printed Name:

Signature:

Typed or CLEARLY Printed Name:

Signature:

Typed or CLEARLY Printed Name:

Signature:

Typed or CLEARLY Printed Name:

Signature:

Typed or CLEARLY Printed Name:

Signature:

Typed or CLEARLY Printed Name:

Signature:

Typed or CLEARLY Printed Name:

Signature: 


\section{Fertility and Sterility.}

\section{STATEMENT OF AUTHORSHIP}

Each author is required to submit a signed Statement of Authorship upon submission. This applies to all submission types including Editorials, Letters to the Editor, etc.

Date: $25102 / 2020$ Manuscript \# (if available):

Manuscript title: Is conception by in-vitro fertilisation associated with altered antenatal and postnatal growth trajectories?

Corresponding author: Sten Turver Authors may elther sign the same form or submit individually

I am an author on this submission, have adhered to all editorial policies for submission as described in the Information for Authors, attest to having met all authorship criteria, and disclosed all potential conflicts of interest for inclusion on the title page of the submission.

Signatures are required - typed signatures are unacceptable.

Typed or CLEARLY Printed Name: ABHA MAMESinw

Typed or CLEARLY Printed Name:

Signature:

Typed or CLEARLY Printed Name:

Signature:

Typed or CLEARLY Printed Name:

Signature:

Typed or CLEARLY Printed Name:

Signature:

Typed or CLEARLY Printed Name:

Signature:

Typed or CLEARLY Printed Name:

Signature:

Typed or CLEARLY Printed Name:

Signature: 
Click here to access/download Downloadable Conflict of Interest Form ICMJE disclosure form_blank_FNS_LA.pdf 
Click here to access/download Downloadable Conflict of Interest Form ICMJE disclosure form_blank_FNSSD.pdf 
Click here to access/download Downloadable Conflict of Interest Form AM ICMJE disclosure form_blank_FNS.pdf 
Click here to access/download Downloadable Conflict of Interest Form EMcoiform .pdf 
Click here to access/download Downloadable Conflict of Interest Form coi_disclosure ST.pdf 